\title{
Characterization of Sodium Hypochlorite Degradation of $\beta$-Glucan in Relation to Its Metabolism in Vivo
}

\author{
Noriko N. MiUra, Naohito Ohno, Yoshiyuki Adachi, and Toshiro YadomaE* \\ Laboratory of Immunopharmacology of Microbial Products, School of Pharmacy, Tokyo University of Pharmacy and \\ Life Science, 1432-1 Horinouchi, Hachioji, Tokyo 192-03, Japan. Received June 17, 1996; accepted August 6, 1996
}

\begin{abstract}
Soluble (SSG, $\beta$-1,3-D-glucan obtained from the culture filtrates of a fungus, Sclerotinia sclerotiorum IFO 9395) and particulate (zymosan) $\beta$-glucans were oxidized by sodium hypochlorite ( $\mathrm{NaClO}$ ), and the oxidized products were analyzed by gel filtration and ion-exchange chromatographies and by limulus G-test to study the metabolism of $\beta$-glucans in vivo. By oxidative degradation, SSG was gradually oxidized to anionic polymers, which decreased the molecular weight and reduced the content of the sidechain at the same time. Zymosan, a particle from fungi cell wall, was easily solubilized to a high molecular weight polysaccharide by oxidative degradation. The elution profiles on ion exchange columns and the limulus G-test reactivity of the products were similar to those of polysaccharides obtained by in vivo experiments using SSG and zymosan. These results suggest that oxidative degradation is the main metabolic pathway of $\beta$-glucans in vivo, and that the sidechains would be oxidized faster than the main chain.
\end{abstract}

Key words $\quad(1 \rightarrow 3)-\beta$-D-glucan; zymosan; SSG; oxidative degradation; limulus test

It is generally accepted that the biological activities of soluble $\beta$-glucans (i.e. sonifilan (SPG; from Schizophyllum commune, ca. 33\% branched), grifolan (GRN; from Grifola frondosa, ca. 33\% branched), and SSG (from Sclerotinia sclerotiorum, ca. $50 \%$ branched)) and particulate $(1 \rightarrow 3)$ $\beta$-D-glucans (i.e. zymosan and zymocel) are significantly different, even though both show beneficial immunopharmacological activities, such as antitumor activity. ${ }^{1-3)}$ The latter can easily induce the production of various inflammatory mediators from phagocytes in vivo and in vitro. Our series of studies has clarified that systemically (i.v.) administered soluble forms of $\beta$-glucans, such as SSG, SPG and GRN, gradually disappeared from the blood stream (the half clearance rate of i.v. administered glucan is approximately $5 \mathrm{~h}$ ) and were deposited in the body, especially in the liver and spleen, over a very long period, i.e. more than a couple of months, without significant structural changes. ${ }^{4,5)}$ By i.p. administration, the blood concentration of the glucan was gradually decreased within several days. The distribution of $\beta$ glucans in major organs administered i.p. and i.v. were similar in both cases. Multiple dosing of GRN or SSG $(250 \mu \mathrm{g} / \mathrm{mouse} / \mathrm{week})$ to autoimmune prone, MRL $l p r / l p r$, mice significantly reduced the clearance rate of the glucan from the blood. $\left.{ }^{6}\right)$ It is known that when glucans are administered to mice, they are then deposited in the liver and spleen over a long period. An increase in the glucan contents in the liver and spleen with multiple dosing would be due to the deposit of these glucans because of the absence of $\beta$-glucan hydrolase in animals. In contrast, it is found that the distribution of particulate glucan in the body was different from that of soluble glucans, in that it is deposited in omentum in the peritoneal cavity by i.p. injection (manuscript in preparation). These facts strongly suggest that the distribution of particulate glucans in the body is different from that of soluble glucans.

From analyses of the deposited glucans in ICR mice, it was found that the molecular weight of the $\beta$-glucan was gradually reduced and acidic groups appeared in the molecules. ${ }^{5,7)}$ These facts suggested that the glucans would be degraded mainly by oxidative degradation mediated by the products of phagocytes, such as $\mathrm{O}_{2}^{-}$, $\mathrm{H}_{2} \mathrm{O}_{2}$, and $\mathrm{HOCl}$. Blocking of functions of the phagocytes by gadlinium chloride reduced the degradation rate. ${ }^{8)}$ In addition, we found extremely high recovery of the glucan, as assessed by a limulus G-test. Considering the fact that the reactivity of the limulus G-test was decreased in the presence of sidechains, ${ }^{9}$ ) it is speculated that the sidechain moiety of the glucan molecule degrades faster than the main chain moieties in the body. To confirm this hypothesis, chemically oxidized glucans were prepared and their limulus G-test reactivity was compared in this paper. Hypochlorous acid $(\mathrm{HOCl})$ is a strong oxidant derived from $\mathrm{H}_{2} \mathrm{O}_{2}$ with the aid of leukocyte-derived peroxidases. Two main peroxidases exist in phagocytes: (1) myeloperoxidase (MPO) in neutrophils and monocytes, and (2) eosinophil peroxidase (EPO). Macrophages may take advantage of the MPO released from other cells at inflammatory sites to convert $\mathrm{H}_{2} \mathrm{O}_{2}$ to $\mathrm{HOCl}^{10)}$ We used a highly branched glucan, SSG, and a particulate glucan preparation, zymosan, for this purpose.

\section{Experimental}

Materials SSG ( $\beta$-glucan from Sclerotinia sclerotiorum IFO 9395) was prepared as described previously. ${ }^{11)}$ Zymosan $A$ was purchased from Sigma Chemical Co. (U.S.A.). Sodium hypochlorite solution and sodium hydroxide were purchased from Wako Pure Chemical Industries, Ltd. Fungitec and zymolyase were from Seikagaku Corp. (Tokyo), and distilled water (DIW) was from Otsuka Co., Ltd. (Tokyo). Toyopearl HW-50 and HW-60 were from Toyo Soda Mfg. Co. (Tokyo). DEAE-Sephadex A25 was from Pharmacia Fine Chemicals, Uppsala (Sweden). Visking tube (MW cutoff; 1000) was from Spectrum Medical Industries Inc.

Measurement of $(\mathbf{1} \rightarrow 3)-\boldsymbol{\beta}$-D-Glucan by G-Test The activation of factor $\mathrm{G}$ by glucans was measured by a colorimetric method, using an $\beta$-glucan quantitative kit (G-test, Seikagaku Corp., Tokyo) which eliminated factor C. The G-test was a specific and sensitive method for $\beta$-glucan detection. Each $(1 \rightarrow 3)-\beta$-D-glucan was dissolved in $0.3 \mathrm{~N} \mathrm{NaOH}$ and diluted with $0.01 \mathrm{~N} \mathrm{NaOH}$. Reactions were performed in flat-bottomed 96-well Toxipet Plates (Seikagaku Corp., Tokyo) as follows. Samples $(25 \mu \mathrm{l})$ were placed in the wells and the Fungitec reagent $(25 \mu \mathrm{l})$ was added to each well. The plate was incubated for $40 \mathrm{~min}$ at $37^{\circ} \mathrm{C}$, and during incubation the absorbance at $405 \mathrm{~nm}$ was measured using a microplate reader 
(Wellreader SK601, Seikagaku Corp.) at $5 \mathrm{~min}$ intervals. Disposable plastics for the tissue culture or the clinic were used, and all glassware was sterilized at $260^{\circ} \mathrm{C}$ for $3 \mathrm{~h}$. All operations were performed under aseptic conditions.

\section{Results}

Preparation of Oxidized $(1 \rightarrow 3)$ - $\boldsymbol{\beta}$-D-Glucans $\quad$ SSG and zymosan were oxidized with three concentrations (added $1.25,6.25$, or $12.5 \mathrm{ml}$ to $45 \mathrm{ml}$ of SSG or zymosan) of sodium hypochlorite solution $(\mathrm{NaClO})$ for $1 \mathrm{~d}$ or $6 \mathrm{~d}$ at room temperature. After the reaction was completed, the reaction mixture was dialyzed extensively with distilled water, and then the non-dialyzable fraction (NDF) was lyophilized and weighed to calculate the recovery. Table 1 summarizes the recovery of the NDF and it was found that the recovery was gradually decreased by increasing $\mathrm{NaClO}$ concentration and extending oxidation period.

Solubility of the resulting NDF were significantly different from the parent SSG and zymosan. SSG is very viscous in aqueous neutral solution, however, the oxidized substances showed lower viscosity (data not shown).

Table 1. Recovery of Non-Dialysable Fractions of Oxidized SSG and Zymosan

\begin{tabular}{ccccc}
\hline \hline $\begin{array}{c}\mathrm{NaClO} \\
(\mathrm{ml})\end{array}$ & $\begin{array}{c}\text { SSG (1 d) } \\
(\%)\end{array}$ & $\begin{array}{c}\text { SSG (6d) } \\
(\%)\end{array}$ & $\begin{array}{c}\text { Zymosan (1 d) } \\
(\%)\end{array}$ & $\begin{array}{c}\text { Zymosan (6d) } \\
(\%)\end{array}$ \\
\hline 0 & 99.5 & 93.9 & 79.8 & 69.9 \\
1.25 & 79.7 & 81.6 & 64.5 & 54.4 \\
6.25 & 73.4 & 83.2 & 59.1 & 46.8 \\
12.5 & 56.6 & 67.7 & 60.9 & 45.3 \\
\hline
\end{tabular}

Each $225 \mathrm{mg}$ of SSG (zymosan), dissolved or suspended in $45 \mathrm{ml}$ of $0.1 \mathrm{~N} \mathrm{NaOH}$, was treated with $1.25,6.25$, or $12.5 \mathrm{ml}$ of sodium hypochlorite solution at room temperature for $1 \mathrm{~d}$ or $6 \mathrm{~d}$. Non-dialysable fraction of each preparation was collected and lyophilized.

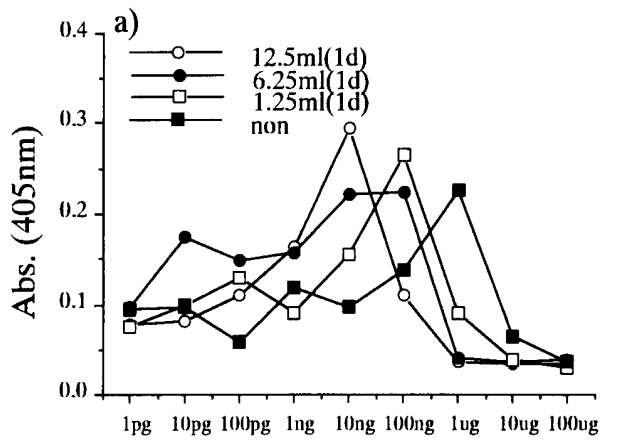

(Concentration $/ \mathrm{ml}$ )

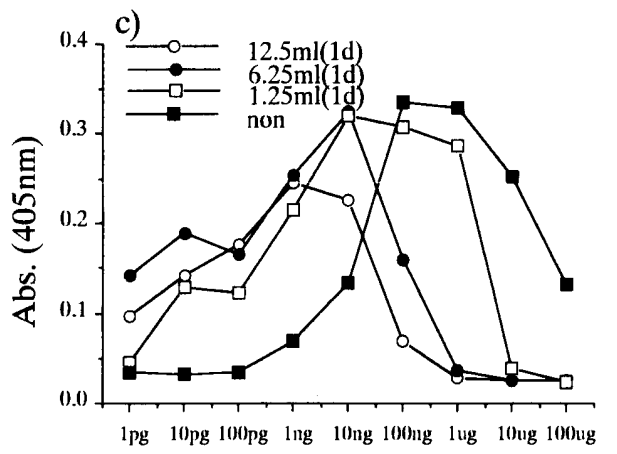

(Concentration $/ \mathrm{ml}$ )
Zymosan is a particulate glucan preparation, however, a significant proportion of the constituents were solubilized during oxidation (Table 2). Of quite importance, only $6 \%$ was remained as a particulate form under the most intensive conditions for $6 \mathrm{~d}$. These facts strongly suggested that a particulate form of the glucan was once solubilized as a larger molecular weight polysaccharide, and simultaneously reducing the molecular weight by oxidation.

Limulus G-Test Reactivity of the Oxidized Products As mentioned in the introduction, we have previously shown that when the contents of the glucan in organ was assessed by the limulus G-test, it was found that recovery of the administered glucan was gradually increased during several weeks and overcame the total amount of the glucan administered. ${ }^{12)}$ To confirm the oxidation mediated increment of the reactivity of the limulus G-test,

Table 2. Solubilization of Zymosan during Oxidation

\begin{tabular}{|c|c|c|c|}
\hline $\mathrm{NaClO}(\mathrm{ml})$ & $\begin{array}{l}\text { ppt } \\
(\mathrm{mg})\end{array}$ & $\begin{array}{l}\text { Sup } \\
(\mathrm{mg})\end{array}$ & $\begin{array}{c}\text { Total } \\
\text { (mg; \% in parenthesis) }\end{array}$ \\
\hline \multicolumn{4}{|l|}{$1 \mathrm{~d}$} \\
\hline 1.25 & 39.1 & 11.5 & $50.6(101)$ \\
\hline 6.25 & 24.6 & 19.6 & $44.2(88.4)$ \\
\hline 12.5 & 3.2 & 41.0 & $44.2(88.4)$ \\
\hline \multicolumn{4}{|l|}{$6 \mathrm{~d}$} \\
\hline 1.25 & 31.6 & 13.2 & $44.8(89.6)$ \\
\hline 6.25 & 2.8 & 41.4 & $44.2(88.4)$ \\
\hline 12.5 & 3.4 & 40.6 & $44.0(88.0)$ \\
\hline
\end{tabular}

Each $50 \mathrm{mg}$ of oxidized zymosan preparation shown in Table 1 was dissolved suspended in $1 \mathrm{ml}$ of distilled water and centrifuged. The precipitate $(\mathrm{ppt}$ ) was washed with $1 \mathrm{ml}$ of distilled water and centrifuged. The supernatant and the washings were combined (sup). Each ppt and sup was lyophilized and their weight was measured

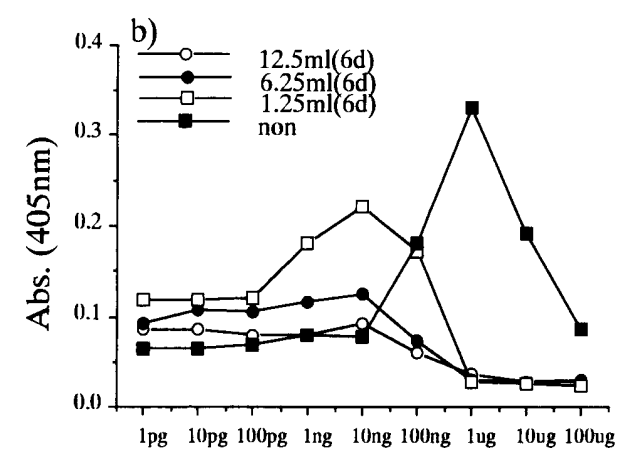

(Concentration /ml)

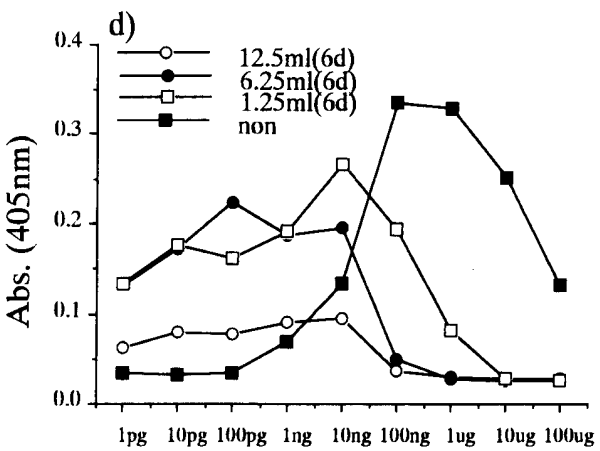

(Concentration $/ \mathrm{ml})$

Fig. 1. Limulus G-Test Reactivity of Oxidized SSG and Zymosan

The reactivity of each of the oxidized fractions to the limulus G-test was measured after sodium hydroxide treatment, as described in Experimental. a), b), SSG: c), d), zymosan. 


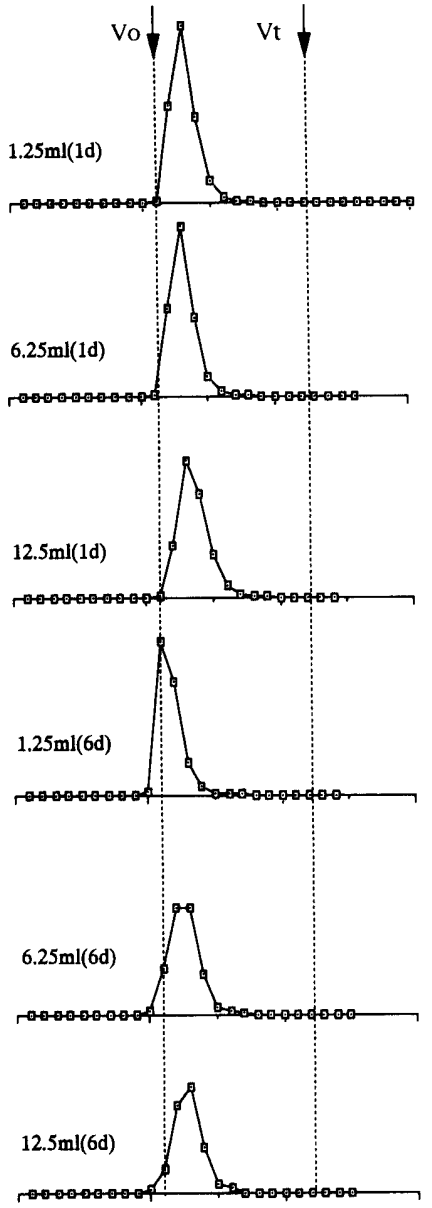

HW 50
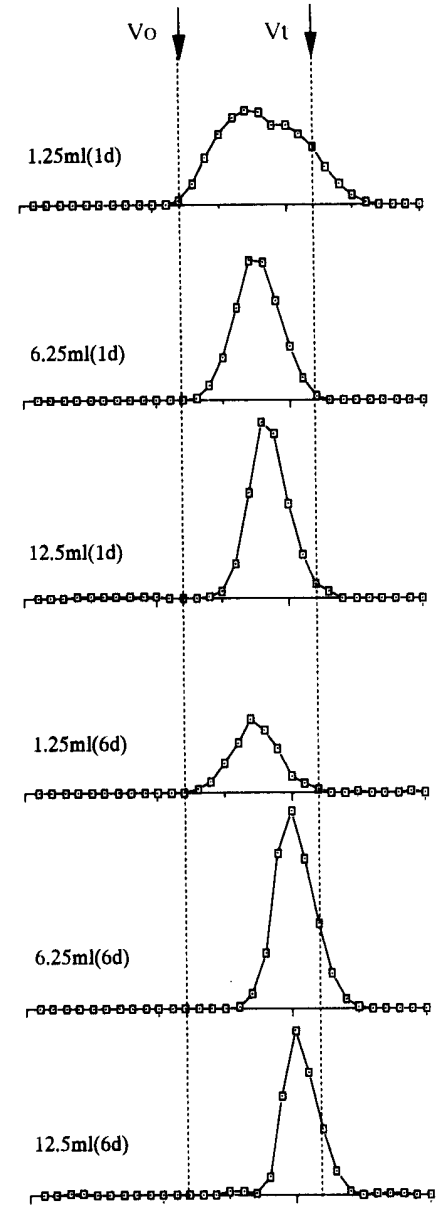

HW60
Fig. 2. Elution Profiles of Oxidized SSG from Columns of Toyopearl HW 50 and HW 60

Each $5 \mathrm{mg}$ of oxidized SSG was applied to a column of Toyopearl HW 50 $(1 \times 35 \mathrm{~cm})$ or a column of Toyopearl HW $60(1 \times 35 \mathrm{~cm})$ equilibrated with $0.3 \mathrm{~N}$ $\mathrm{NaOH}$, and fractions of each $1.1 \mathrm{ml}$ were collected. The carbohydrate concentration in each fraction was measured by the phenol-sulfuric acid method. Arrows indicate void (dextran T 2000) and bed (glucose) volumes.

the reactivity of the NDF fractions were tested. As shown in Fig. 1, the reactivity of the NDF fractions of both SSG and zymosan were higher than those of the parent materials. Reactivity of oxidized SSG prepared by using $12.5 \mathrm{ml}$ of $\mathrm{NaClO}$ to oxidize for $1 \mathrm{~d}(12.5 ; 1 \mathrm{~d})$ was about 100 times higher than the parent SSG, and that of oxidized zymosan treated by same condition was about 50 times higher than the parent zymosan. Of interest, however, the reactivity was significantly reduced after intensive oxidation $(12.5 ; 6 \mathrm{~d})$. In the case of zymosan, increased reactivity might be strongly related to the solubilization of the cell wall glucan during oxidation, as shown in Table 2. In contrast, increased reactivity of the oxidized SSG might be due to the reduced degree of branching, as discussed in greater detail below.

Physicochemical Properties of the Oxidized Products We have already shown that SSG recovered from the liver one month after i.p. administration had a smaller molecular weight than the parent SSG and was, at least in part, bound to a column of DEAE-Sephadex, and eluted by sodium chloride. ${ }^{8)}$ We tested the properties of the oxidized products using the same procedure. Figure 2 shows the elution profiles of the NDF fractions of oxidized SSG
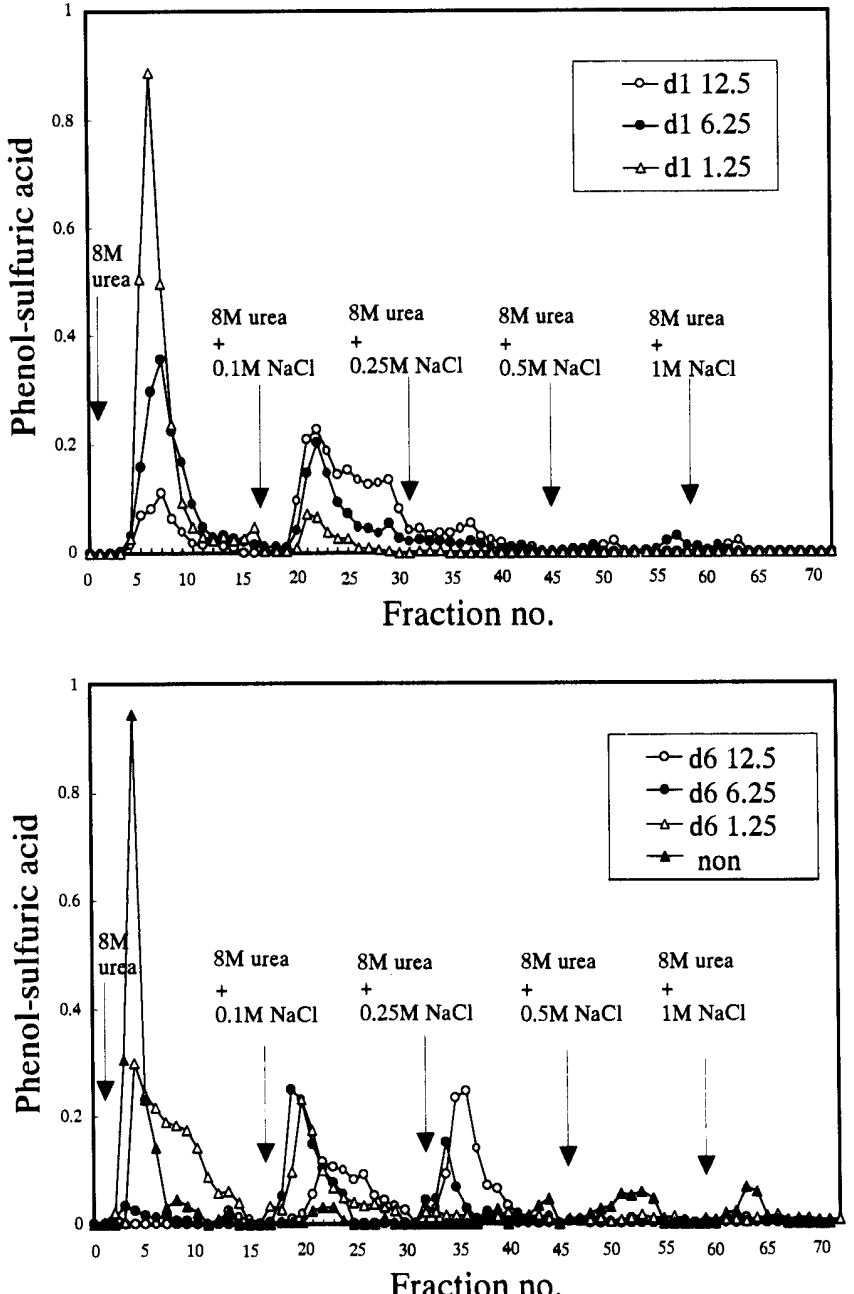

Fig. 3. Elution Profiles of Oxidized SSG from a Column of DEAESephadex A-25 $\left(\mathrm{Cl}^{-}\right)$

Each $5 \mathrm{mg}$ of oxidized SSG dissolved in $8 \mathrm{M}$ urea was applied to a column of DEAE-Sephadex A-25 $\left(\mathrm{Cl}^{-}\right)$equilibrated with $8 \mathrm{M}$ urea. Bound fractions were eluted by $8 \mathrm{M}$ urea containing $0.1 \mathrm{M}, 0.25 \mathrm{M}, 0.5 \mathrm{M}$, and $1 \mathrm{M} \mathrm{NaCl}$ sequentially. Fractions of each $1.1 \mathrm{ml}$ were collected and the carbohydrate concentration in each fraction was measured by the phenol-sulfuric acid method.

on a column of Toyopearl HW-50 and from HW-60. As expected, the molecular weight of the NDF fractions gradually decreased with increasing the concentration of $\mathrm{NaClO}$ or extending the reaction conditions. Figure 3 shows the elution profile of the NDF fractions of oxidized SSG from a column of DEAE-Sephadex. It was found that the majority of the NDF fractions of oxidized SSG were bound to the column, suggesting the appearance of anionic groups in SSG. Comparing the elution profiles of the NDF fractions on a DEAE-Sephadex column, a higher salt concentration was required for eluting the products of stronger reaction conditions. Especially in the case of $6 \mathrm{~d}$ of oxidation, a significant amount of the product was eluted at $0.25 \mathrm{M} \mathrm{NaCl}$ fraction. Properties of the oxidized fractions are similar to those of the fractions obtained in vivo by metabolically tritium-labeled SSG. ${ }^{5)}$

Zymolyase Digestion of the Oxidized Products As shown above, the reactivity of the limulus G-test was increased by oxidation. To confirm the sidechain degradation, a representative fraction of the oxidized SSG $(12.5 ; 1 \mathrm{~d})$ was subjected to zymolyase digestion and 


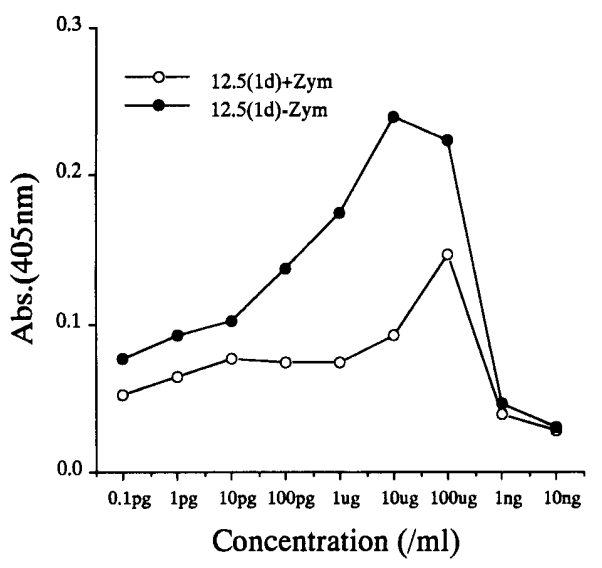

Fig. 4. Limulus G-Test Reactivity of Oxidized SSG before and after Zymolyase Treatment

Oxidized SSG (12.5 (1 d); $2 \mathrm{mg}$ ) was dissolved in $50 \mathrm{~mm}$ acetate buffer (pH 6.0) and mixed with $200 \mu \mathrm{g}$ of zymolyase $20 \mathrm{~T}$. After $24 \mathrm{~h}$ of incubation at $37^{\circ} \mathrm{C}$, the resulting reaction products were treated with sodium hydroxide and the limulus G-test reactivity was measured as described in Experimental.

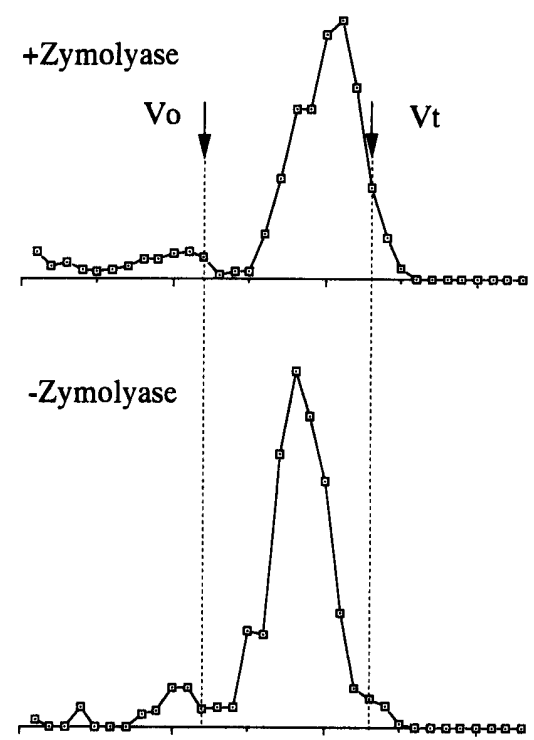

Fig. 5. Elution Profiles of Oxidized SSG from a Column of Toyopearl HW 60 before and after Zymolyase Treatment

Oxidized SSG $(12.5(1 \mathrm{~d}) ; 2 \mathrm{mg}$ ) was dissolved in $50 \mathrm{~mm}$ of an acetate buffer $(\mathrm{pH}$ 6.0) and mixed with $200 \mu \mathrm{g}$ of zymolyase $20 \mathrm{~T}$. After $24 \mathrm{~h}$ of incubation at $37^{\circ} \mathrm{C}$ the resulting reaction products were applied to a column of Toyopearl HW 60 $(1 \times 35 \mathrm{~cm})$ equilibrated with $0.3 \mathrm{~N} \mathrm{NaOH}$, and fractions of each $1.1 \mathrm{ml}$ were collected. The carbohydrate concentration in each fraction was measured by the phenol-sulfuric acid method. Arrows indicate void (dextran T 2000) and bed (glucose) volumes.

analyzed by the limulus reactivity (Fig. 4) and the molecular weight (Fig. 5). SSG is known to resist zymolyase digestion. ${ }^{13)}$ It was apparent that the reactivity of oxidized SSG to the limulus G-test was decreased, and the molecular weight of the oxidized SSG was reduced by the zymolyase treatment. However, the reactivity still remained. These facts strongly suggested that at least part of the sidechain was removed from SSG during oxidation.

\section{Discussion}

The primary structure of the $(1 \rightarrow 3)-\beta$-D-glucan from fungi is usually illustrated simply as a 3-linked $\beta$-Dglucopyranosyl residue (main chain) in the presence or absence of 6 -linked $\beta$-D-mono-glucopyranosyl residue (sidechain). Results of the X-ray crystallography of $(1 \rightarrow 3)-\beta$-D-glucan strongly suggest that the structure is a straight rod in which three main chain moieties are located inside by inter-chain hydrogen bonding to form a "triple helix" structure. The side-chain moiety is suggested to be localized outside of the rod. Because of the fact that the extracellular polysaccharide from fungi is usually bio-synthesized by a relatively simple pathway, this model well classifies the various structures of the glucans. In contrast, the structure of the fungal cell wall polysaccharide (particle) is thought to have a complex architecture, even though the major linkages are 3-linked and 6 -linked $\beta$-glucopyranosyl residues.

In this paper, we have found that the particle was relatively easily solubilized by oxidative degradation. It is generally accepted that phagocytes can produce reactive oxygen species by stimulation with the particles. It is probable that the particles are solubilized by oxidative degradation in vivo. Previously, we examined the solubilization of $\beta$-glucans by phagocytes in vitro. ${ }^{14)}$ However, the process could not be completed during an in vitro cell culture within two days. These facts suggested that the complete dissolution of the particle might require a longer period in vivo.

$\beta$-Glucans possess at least two conformations, single and triple helixes, in a gel state. In both of these conformations, the interchain interaction is thought to be induced mainly by a main chain moiety. The sidechain is suggested to be localized outside of the rod and might be more easily oxidized by an active oxygen species. We already confirmed that the degree of branching of SSG is about $50 \%$ and could not be degraded by zymolyase digestion. ${ }^{13)}$ The data shown in Fig. 4, in which oxidized SSG was partially degraded by zymolyase digestion, strongly support the assumption that the degree of branching in oxidized SSG is less than in the parent glucan.

$\beta$-Glucan is an important substance for cancer immunotherapy. We have already confirmed that the metabolism of the glucan in the body is quite slow in vivo, because of the absence of a hydrolyzing enzyme. ${ }^{\text {? }}$ Available evidence strongly suggests that oxidative degradation is the main metabolic pathway. Studies on the metabolic inactivation of $\beta$-glucan would be quite important in establishing therapeutic strategy.

Acknowledgments We express our sincere thanks to Miss Nozomi Yamane for her excellent technical assistance.

\section{References}

1) Ohno N., Egawa Y., Hashimoto T., Adachi Y., Yadomae T., Biol. Pharm. Bull., 19, 608-612 (1996).

2) Miura T., Ohno N., Suda M., Noriko N. M., Shimada S., Yadomae T., Biol. Pharm. Bull., 18, 1797-1801 (1995).

3) Ohno N., Asada N., Adachi Y., Yadomae T., Biol. Pharm. Bull., 18, 126-133 (1995).

4) Miura N. N., Ohno N., Adachi Y., Aketagawa J., Tamura H., Tanaka S., Yadomae T., Biol. Pharm. Bull., 18, 185-189 (1995).

5) Suda M., Ohno N., Adachi Y., Yadomae T., J. Pharmacobio-Dyn., 15, 417-426 (1992).

6) Miura N. N., Ohno N., Aketagawa J., Tamura H., Tanaka S., Yadomae T., FEMS Immunol. Med. Microbiol., 13, 51-57 (1996). 
7) Nono I., Ohno N., Masuda A., Oikawa S., Yadomae T., J. Pharmacobio-Dyn., 14, 9-19 (1991).

8) Suda M., Ohno N., Hashimoto T., Koizumi K., Adachi Y., Yadomae T., FEMS Immunol. Med. Microbiol., 15, 93-100 (1996).

9) Ohno N., Emori Y., Yadomae T., Carbohydr. Res., 207, 311-318 (1990).

10) Walker B. A. M., Fantone J. C., "Immunology and Inflammation," ed. by Signal L. H., Ron Y., McGraw-Hill, U.S.A., 1994, pp.
$359-386$.

11) Suzuki I., Hashimoto K., Ohno N., Tanaka H., Yadomae T., Int. J. Immunopharmac., 11, 761-769 (1989).

12) Miura T., Ohno N., Suda M., Miura N. N., Shimada S., Yadomae T., Biol. Pharm. Bull., 18, 1797-1801 (1995).

13) Ohno N., Terui T., Chiba N., Kurachi K., Adachi Y., Yadomae T., Chem. Pharm. Bull., 43, 1057-1060 (1995).

14) Nagi N., Ohno N., Tanaka S., Aketagawa J., Shibata Y., Yadomae T., Chem. Pharm. Bull., 40, 1532-1536 (1992). 